\title{
Clinical and Genetic Study of Chronic Kidney Disease
}

\author{
${ }^{1}$ Elena V. Nekipelova, ${ }^{2}$ Olga N. Novakova, ${ }^{3}$ Vladimir F. Kulikovskij, ${ }^{4}$ Nina I. Zhernakova, ${ }^{5}$ Mikhail I. Churnosov \\ Belgorod State University, 308015, Belgorod, Pobeda Street, 85, Russia \\ Email: litovkina@bsu.edu.ru
}

Received: 22 ${ }^{\text {nd }}$ June 2018, Accepted: 01 ${ }^{\text {st }}$ August 2018, Published: 31 $^{\text {st }}$ August 2018

\begin{abstract}
This paper presents the results of the study of the interrelationships of polymorphic loci of chemokines (rs1719153, rs4512021, rs2107538, rs2857657, rs1801157) with features of humoral immunity in patients with chronic glomerulonephritis. It was established that the concentration of immunoglobulins $A$ and $G$ in the group of patients with chronic glomerulonephritis was significantly higher than in the control group $(\mathrm{p}<0.001)$. It was revealed that the genotype +1931TT CCL4 (rs1719153) is a marker of an increased level of immunoglobulin $\mathrm{G}$ in patients with chronic glomerulonephritis $(\mathrm{p}=0.05)$.
\end{abstract}

Keywords: Chronic Glomerulonephritis, Chemokines, Gene Polymorphism, Immunoglobulins, Chronic Kidney Disease.

\section{Introduction}

Chronic glomerulonephritis (CGN) holds a special place in the structure of chronic kidney diseases as one of the main causes of terminal renal failure and associated disability and mortality (Litovkina et al., 2014; Sorokina et al., 2016). According to available data, glomerulonephritis is considered as an immunemediated renal disease with diffuse proliferativeexudative lesion of the glomerular apparatus of the kidneys, caused by imbalance of regulatory mechanisms of immunocompetent cells and renal glomerulus cells with the involvement of other components of the kidney tissue in the pathological process (Dudnyk et al., 2015; Nekipelova et al., 2016). Despite the fact that the role of the main classes of immunoglobulins ( $\mathrm{Ig}$ ) in the development of CGN is currently undoubtable, there are relatively few publications devoted to studies of immunoglobulin in CGN, available in the literature. Immunoglobulins are classified as specific humoral immunity factors that specifically recognize a wide variety of antigens, interact with other immunocompetent cells having corresponding receptors, and activate the complement system (Arias et al., 2013).

The Ig level in peripheral blood is one of the often tested parameters of the immune system, characterizing the immune status in normal state and in immunopathological disorders (Floccari et al., 2007). Therefore, interest in the study of immunological indicators such as $\operatorname{IgA}, \operatorname{IgM}, \operatorname{IgG}$ is not accidental, but is caused by the desire to evaluate the humoral unit of the immune response in patients with CGN.

A diversity of clinical manifestations of CGN, significant differences in the rate of decrease in renal function with the same severity of risk factors allows us to discuss the importance of the genetic component in the formation of a predisposition to this disease and determination of the features of its course. According to modern literature data, among the candidate CGN genes, chemokines are especially prominent (Azmandian et al., 2012). Chemokines are peptide low-molecular immunomodulators with chemoattractant properties (Stangou et al., 2016). They control the migration of different types of leukocytes with the relevant receptors from the bloodstream to the tissues, inflammation and autoimmune process foci, participate in activation and differentiation of leukocytes, angiogenesis, fibrogenesis (Wada, 2008; Eddy, 2014). However, the results of molecular genetic studies of chronic glomerulonephritis of different authors often differ and do not give an unambiguous answer to the question of the pathogenetic role of individual polymorphisms of chemokine genes (Bagci et al., 2015; Dudnyk et al., 2015; Sorokina et al., 2016).

The objective of this research was to study the interrelationships of polymorphic loci of chemokines (rs1719153, rs4512021, rs2107538, rs2857657, rs1801157) with features of humoral immunity in patients with chronic glomerulonephritis.

\section{Materials and Methods}

For the study, a sample of 700 people was formed: 238 patients with chronic glomerulonephritis and 462 individuals of the control group. Samples of patients and controls included Russian residents of the Central Chernozem Region of the Russian Federation, who had no family ties with each other. Patients belonged to the corresponding group after being diagnosed with the disease, confirmed by clinical and laboratoryinstrumental methods of examination in the nephrology department of St. Joasaph Belgorod Regional Clinical Hospital. Exclusion criteria for a group of CGN patients were diabetes mellitus (in history or identified by the test results) and hypertension. All patients signed an informed consent for inclusion in the study and use of their data. The control group included individuals without kidney disease and hypertension.

As the material for the study we used 8-9 ml of venous blood taken from the cubital vein of a proband. A genomic DNA was isolated from peripheral blood by the method of standard phenol-chloroform extraction (Miller et al., 1988). Analysis of the investigated loci was carried out by the method of polymerase chain reaction of DNA synthesis with the use of standard primers and probes. 
The level of immunoglobulins $A, M$ and $G$ was determined by enzyme immunoassay (ELISA) in serum samples with standard sets in accordance with the manufacturer's instructions.

The test materials were processed by statistical methods using Statistica 8.0. The correspondence of the observed distribution of genotypes to the expected one was analyzed with the use of $\chi^{2}$ criterion, based on the Hardy-Weinberg equilibrium. A comparative analysis of the allele and genotype frequencies of the loci studied between the control group and patients used the $\chi^{2}$ criterion with the Yates correction for continuity. The calculations were made in $2 \times 2$ conjugation tables. Statistical differences were considered significant at $\mathrm{p}<0.05$.

\section{Results and Discussion}

During the study of 238 patients with chronic glomerulonephritis and 462 individuals of the control group a full comparability of sample data in terms of age, nationality and place of birth was established.

We conducted a molecular genetic typing of the following polymorphic loci: +1931A/T CCL4 (rs1719153), A/G CXCL11 (rs4512021), -403A/G CCL5 (rs2107538), C/G CCL2 (rs2857657), -801G/A CXCL12 (rs1801157). The selection of genetic marker data was determined by the pathogenetic significance of chemokine determinants for CGN (Anders et al., 2010). The study of the frequencies of alleles of studied polymorphisms of chemokine genes revealed that for all

\begin{tabular}{|c|c|c|c|c|}
\hline & \multirow{2}{*}{ Genotypes } & \multicolumn{3}{|c|}{ Concentration of Immunoglobulins (g/l) } \\
\hline & & IgA & IgM & IgG \\
\hline \multirow{3}{*}{ rs4512021 } & AA & $3.64 \pm 0.23$ & $2.92 \pm 0.14$ & $19.01 \pm 0.87$ \\
\hline & $\mathrm{AG}, \mathrm{GG}$ & $3.82 \pm 0.19$ & $2.82 \pm 0.12$ & $18.82 \pm 0.84$ \\
\hline & $\mathrm{p}$ & 0.39 & 0.74 & 0.81 \\
\hline \multirow[t]{3}{*}{ rs2107538 } & $-403 \mathrm{GG}$ & $3.65 \pm 0.17$ & $2.99 \pm 0.10$ & $21.14 \pm 0.75$ \\
\hline & $-403 \mathrm{AA},-403 \mathrm{GA}$ & $3.77 \pm 0.25$ & $2.84 \pm 0.15$ & $18.52 \pm 1.01$ \\
\hline & $\mathrm{p}$ & 0.29 & 0.60 & 0.36 \\
\hline \multirow[t]{3}{*}{ rs2857657 } & $\mathrm{CC}$ & $3.85 \pm 0.14$ & $2.81 \pm 0.09$ & $18.98 \pm 0.58$ \\
\hline & $\mathrm{CG}, \mathrm{GG}$ & $3.49 \pm 0.94$ & $2.84 \pm 0.61$ & $18.77 \pm 2.68$ \\
\hline & $\mathrm{p}$ & 0.60 & 0.70 & 0.85 \\
\hline \multirow[t]{3}{*}{ rs1801157 } & $-801 G G$ & $3.60 \pm 0.16$ & $2.80 \pm 0.11$ & $18.71 \pm 0.98$ \\
\hline & -801GA, -801AA & $4.07 \pm 0.26$ & $2.86 \pm 0.15$ & $19.50 \pm 0.71$ \\
\hline & $\mathrm{p}$ & 0.12 & 0.51 & 0.40 \\
\hline \multirow[t]{3}{*}{ rs1719153 } & $+1931 \mathrm{TT}$ & $3.49 \pm 0.39$ & $2.95 \pm 0.18$ & $22.02 \pm 2.02$ \\
\hline & +1931AA, +1931AT & $3.82 \pm 0.31$ & $3.05 \pm 0.96$ & $18.53 \pm 0.59$ \\
\hline & $\mathrm{p}$ & 0.49 & 0.57 & 0.05 \\
\hline
\end{tabular}

Notes: SNP, single-nucleotide polymorphism; IgA, immunoglobulin A; IgM, immunoglobulin M; IgG, immunoglobulin $\mathrm{G}$.

Table 1. The Level of Immunoglobulins in Patients with Chronic Glomerulonephritis (g/l), Depending on the Genetic Polymorphisms of Chemokines loci in the group of CGN patients and in the control sample the empirical distribution of genotypes corresponds to the theoretically expected one at HardyWeinberg equilibrium $(\mathrm{p}>0.05)$.

A comparative analysis of the frequency distribution of alleles and genotypes of polymorphic markers of chemokine genes showed no statistically significant differences between the patients with CGN and those of

Further, the levels of immunoglobulins A, M, G were studied in patients with CGN. It was found that patients with CGN had a higher content of immunoglobulins A (3.75 g/l) and G (18.85 g/l) compared to the control group $(2.98 \mathrm{~g} / \mathrm{l}$ and $12.42 \mathrm{~g} / \mathrm{l}$, respectively, $\mathrm{p}<0.001)$. The level of immunoglobulin $\mathrm{M}$ in patients and in control group was the same $(\mathrm{p}>0.05)$.

The study of the interrelations of genetic chemokine polymorphisms with the level of immunoglobulins in patients with CGN revealed statistically significant associations of the polymorphic genetic locus + 1931A/T CCL4 (rs1719153) with the level of immunoglobulin $G$ (Table 1). Individuals with the genotype +1931TT CCLA had concentration of immunoglobulin $\mathrm{G}$ equal to 22.02-2.02 $\mathrm{g} / \mathrm{l}$, which is significantly higher than in the patients with genotypes +1931AA and + 1931AT CCLA (18.53 $\pm 0.59 \mathrm{~g} / \mathrm{l}$, $\mathrm{p}=0.05)$. the control group $(\mathrm{p}>0.05)$. 
According to modern literature sources, among chemokines, a macrophage inflammatory protein-1 plays a significant role in the development of inflammatory reactions in the body (Stasikowska et al., 2007). This chemokine is a low-molecular protein of the $\beta$-family of CC-chemokines. CCL4, along with the chemoattractant property (predominantly for $\mathrm{CD}^{+}$ cells) induces the attachment of circulating human lymphocytes to the endothelium (Stasikowska et al., 2007). There is evidence of an increase in the level of CCL3 in individuals with coronary artery disease (Ardigo et al., 2005) and CCL4 in those with breast cancer (Chavey et al., 2007). The available literature on the role of CCL4 in CGN in humans is very limited. A significant increase in the level of CCL3 and CCL4 in the peripheral blood of patients with diabetic glomerulonephritis was described (Stasikowska et al., 2007). It should be noted that the available literature contains no works devoted to the study of the interrelations of polymorphic loci of chemokines with the levels of immunoglobulins $\mathrm{A}, \mathrm{M}$ and $\mathrm{G}$ in patients with chronic glomerulonephritis.

\section{Conclusion}

Thus, within the framework of this paper, the study of associations of polymorphic loci of chemokines (rs1719153, rs4512021, rs2107538, rs2857657, rs1801157) with features of humoral immunity in patients with chronic glomerulonephritis, residing in the Central Chernozem Region of Russia, established that the genotype +1931TT CCL4 (rs1719153) with a higher level of immunoglobulin $G$ in patients with chronic glomerulonephritis $(p=0.05)$. It was established that the concentration of immunoglobulins $\mathrm{A}$ and $\mathrm{G}$ in the group of patients with chronic glomerulonephritis was significantly higher than in the control group $(\mathrm{p}<0.001)$.

\section{References}

1. Anders, H. J., Sayyed, S.A., Vielhauer, V., 2010. Questions about chemokine and chemokine receptor antagonism in renal inflammation. Nephron. Exp. Nephrol, 114(2): 33-38.

2. Ardigo, D., Tabibiazar, R., Olshen R., 2005. Signature pattern of circulating chemokines can improve the identification of coronary artery disease. Diabetologia, 48(1): 406-407.

3. Arias, L.F., Prada, M.C., Velez-Echeverri, C., Serna-Higuita, L.M., Serrano-Gayubo, A.K., Ochoa, C.L., Vanegas-Ruiz, J.J., 2013. IgM nephropathy in children: clinicopathologic analysis. Nefrologia, 33(4): 532-538.

4. Azmandian, J., Mandegary, A., Saber, A., 2012. Chemokine Receptor 2-V64I and Chemokine Receptor 5-Delta32 Polymorphisms and Clinical Risk Factors of Delayed Graft Function and Acute Rejection in Kidney Transplantation. Iran. J. Kidney Dis., 6(1): 56-62.

5. Bagci, B., Bagci, G., Candan, F., Ozdemir, O., Sezgin, I., 2015. The protective effect of MCP-
$1-2518$ A $>$ G promoter polymorphism in Turkish chronic renal failure patients requiring long-term hemodialysis. Int Urol Nephrol, 47(3): 551-556.

6. Chavey, C., Bibeau, F., Gourgou-Bourgade, S., Burlinchon, S., Boissiere, F., Laune, D., Roques, S., Lazennec, G., 2007. Oestrogen receptor negative breast cancers exhibit high cytokine content. Breast. Cancer Res., 9(1): R15.

7. Dudnyk, V., Zvenigorodska, A., Guminska, G., 2015. Genetic aspects of chronic glomerulonephritis. Lik Sprava, 1(2): 59-60

8. Eddy, A.A., 2014. Overview of the cellular and molecular basis of kidney fibrosis. Kidney Int., 4(1): 2-8.

9. Floccari, F., Palla, R., Polito, P., Campo, S., Aloisi, C., Buemi, M.G., 2007. Intravenous immunoglobulins in the treatment of glomerulopathies. Ital Nefrol., 24(4): 311319.

10. Litovkina, O.N., Nekipelova, E.V., Sirotina, S.S., Yakunchenko, T.I., Efremova, O.A., Sorokina, I.N., 2014. Polymorphism of Vascular Homeostasis Genes and Progression of Chronic Kidney Disease in Patients with Chronic Glomerulonephritis. Research Journal of Pharmaceutical, Biological and Chemical, 5(5): 1079-1082.

11. Miller, S.A., Dykes, D.D., Polesky, H.F., 1988. A simple salting out procedure for extracting DNA from human nucleated cells. Nucleic acids research, 16(3): 1215

12. Nekipelova, E.V., Novakova, O.N., Yakunchenko, T.I., Krikun, E.N., Zhernakova, N.I., Efremova, O.A., 2016. Clinical and Genetic Research of Chronic Glomerulonephritis.Research Journal of Pharmaceutical, Biological and Chemical Sciences, 7(6): 3222-3227.

13. Sorokina, I., Nekipelova, E., Yakunchenko, T., Novakova, O., Krikun, E., Zhernakova, N., Polonikov, A., 2016. Genetic Factors of Decreased Kidney Function in Patients with Chronic Glomerulonephritis. Research Journal of Pharmaceutical, Biological and Chemical Sciences, 7(6): 3228-3232.

14. Stangou, M., Bantis, C., Skoularopoulou, M., Korelidou, L., Kouloukouriotou, D., Scina, M., Labropoulou, I.T., Kouri, N.M., Papagianni, A., Efstratiadis G. 2016. Th1, Th2 and Treg/T17 cytokines in two types of proliferative glomerulonephritis. Indian J Nephrol, 26(3): 159-166.

15. Stasikowska, O., Wagrowska-Danilewicz, M., 2007. Chemokines and chemokine receptors in glomerulonephritis and renal allograft rejection. Med. Sci. Monit., 13(2): 31-36.

16. Wada, T., Matsushima, K., Kaneko, S., 2008. The role of chemokines in glomerulonephritis. Front. Biosci., 13: 3966-3974. 